\title{
Expression of carbonic anhydrase IX is associated with poor prognosis through regulation of the epithelial-mesenchymal transition in hepatocellular carcinoma
}

\author{
SATOSHI HYUGA ${ }^{1}$, HIROSHI WADA ${ }^{1}$, HIDETOSHI EGUCHI ${ }^{1}$, TORU OTSURU ${ }^{1}$, YOSHIFUMI IWGAMI ${ }^{1}$, \\ DAISAKU YAMADA ${ }^{1}$, TAKEHIRO NODA ${ }^{1}$, TADAFUMI ASAOKA ${ }^{1}$, KOICHI KAWAMOTO ${ }^{1}$, KUNIHITO GOTOH ${ }^{1}$, \\ YUTAKA TAKEDA $^{1,3}$, MASAHIRO TANEMURA ${ }^{1,4}$, KOJI UMESHITA $^{2}$, YUICHIRO DOKI ${ }^{1}$ and MASAKI MORI ${ }^{1}$ \\ ${ }^{1}$ Department of Gastroenterological Surgery, ${ }^{2}$ Division of Health Sciences, Graduate School of Medicine, \\ Osaka University, Osaka 565-0871, ${ }^{3}$ Department of Surgery, Kansai Rosai Hospital, Amagasaki 660-8511, \\ ${ }^{4}$ Department of Surgery, Osaka Police Hospital, Osaka 534-0035, Japan
}

Received February 6, 2017; Accepted July 3, 2017

DOI: 10.3892/ijo.2017.4098

\begin{abstract}
Carbonic anhydrase 9 (CA9) is a plasma membraneassociated isoenzyme that catalyzes $\mathrm{pH}$ regulation under hypoxic conditions. CA9 is transcriptionally regulated by hypoxia-inducible factor 1 . Recent studies reported that hypoxia also promoted the epithelial-mesenchymal transition (EMT) in various cancers. In the present study, we evaluated the relationship between CA9 expression and EMT in vitro with two hepatoma cell lines. We also examined the clinical significance of CA9 expression in 117 consecutive patients that underwent hepatectomies for hepatocellular carcinoma (HCC). We evaluated CA9 expression and EMT induction under hypoxia with quantitative RT-PCR, western blot analysis and immunofluorescence staining, in $\mathrm{HuH7}$ and HepG2 cells. We knocked down CA9 expression with small interfering RNA to evaluate the relationship between CA9 and EMT. We found that hypoxia induced CA9 expression in HCC cells and promoted EMT, evidenced by a loss of E-cadherin and an increase in $\mathrm{N}$-cadherin. Twist, a transcriptional regulator of EMT, was also upregulated with hypoxia. The CA9 deficiency attenuated hypoxia-induced changes in E-cadherin and $\mathrm{N}$-cadherin. Immunohistochemical evaluations of patient samples showed that CA9 was expressed in $50.4 \%$ of patients (59/117). However, patients with and without CA9 expression were not significantly different in clinicopathological
\end{abstract}

Correspondence to: Dr Hidetoshi Eguchi, Department of Gastroenterological Surgery, Graduate School of Medicine, Osaka University, Yamadaoka 2-2, Suita City, Osaka 565-0871, Japan E-mail: heguchi@gesurg.med.osaka-u.ac.jp

Abbreviations: CA9, carbonic anhydrase 9; EMT, epithelialmesenchymal transition; HIF1, hypoxia-inducible factor 1; RT-PCR, reverse transcription PCR

Key words: hepatocellular carcinoma, carbonic anhydrase 9, epithelial-mesenchymal transition, hypoxia, prognosis factors. Nevertheless, a multivariate analysis showed that CA9 expression was an independent factor for both recurrence and prognosis among patients that underwent curative surgery for HCC. In conclusion, this study revealed that CA9 expression was a pivotal predictive factor for poor prognosis after radical surgery for HCC. Moreover, the CA9 regulation of the expression of EMT-related molecules represented a mechanism that enhanced malignant potential.

\section{Introduction}

Hepatocellular carcinoma (HCC) is one of the most common malignancies; it is the third leading cause of cancer-related deaths worldwide (1). HCC arises when the liver is damaged by various liver diseases, such as chronic viral hepatitis or alcoholic liver cirrhosis (2-4). The prognosis of patients with HCC is generally poor, because most patients are diagnosed in the advanced stages, with intra- or extra-hepatic metastasis $(5,6)$, and without an indication of surgery. Consequently, postoperative recurrence rates are high, even when radical resections are performed (7). The postoperative recurrence rates at 3 and 5 years were 61.2 and $85.7 \%$, respectively (8). Therefore, it is crucial to establish new molecular targeting therapies for HCC by searching for molecular markers that correlate with tumor progression and poor prognosis.

Members of the carbonic anhydrase (CA) family are zinc metalloenzymes that catalyze the hydration of carbon dioxide and produce bicarbonate and protons. In various living organisms, CAs function as a modulator of $\mathrm{pH}$ and ion transports in many biological processes. Carbonic anhydrase IX (CA9) is an integral plasma membrane isoenzyme with an extracellular catalytic domain $(9,10)$. CA9 expression is elevated in various types of tumors compared to its expression in non-tumor tissues, and it is strongly induced under hypoxic conditions. In response to hypoxia, CA9 gene transcription is sensitively regulated by hypoxia-inducible factor 1 (HIF1). HIF1 plays a pivotal role in the hypoxic response and it mediates many phenomena (11).

Several studies have shown that CA9 expression in tumor cells was related to poor prognoses. The finding suggested that 
CA9 might be a useful marker of aggressive malignant potential and progression in various cancers, including lung $(12,13)$, breast (14,15), renal (16), bladder (17) and cervical (18) cancers. Although the detailed function of CA9 remains to be clarified, a few studies have suggested that upregulation of CA9 worsened prognoses by enhancing the malignant potential of tumors.

The epithelial-mesenchymal transition (EMT) is a process where epithelial cells lose cell polarity and cell adhesion capabilities and they gain migratory and invasive capacities. Therefore, EMT plays important roles in progression, because it allows tumor cells to invade to other tissues and migrate to distant organs (19). Recent reports have also shown that hypoxic conditions correlated with the induction of EMT in various tumor cells (20-22). Moreover, Svastová et al (23) reported that upregulation of CA9 expression promoted a loss of cell-to-cell adhesion via the downregulation of E-cadherin expression.

This study aimed to clarify the role of CA9 in HCC progression. To that end, we evaluated the correlation between CA9 and EMT in two hepatoma cell lines, and we also examined the clinical significance of CA9 expression in 117 consecutive patients that underwent curative resections for HCC.

\section{Materials and methods}

Cell culture. The human hepatoma cell lines, HuH7 and HepG2, were purchased from the Japan Cancer Research Resources Bank (Tokyo, Japan). Cells were cultured and maintained in Dulbecco's modified Eagle's medium supplemented with $10 \%$ fetal bovine serum (FBS) and $500 \mu \mathrm{g} / \mathrm{ml}$ penicillin-streptomycin, at $37^{\circ} \mathrm{C}$ in a humidified incubator with $5 \% \mathrm{CO}_{2}$ in air.

Drugs and reagents. Cobalt chloride hexahydrate $\left(\mathrm{CoCl}_{2} \cdot 6 \mathrm{H}_{2} \mathrm{O}\right)$, which produces pseudo-hypoxia by inducing HIF1 $\alpha$ expression, was purchased from Sigma-Aldrich (St. Louis, MO, USA). We used the following antibodies for immunohistochemistry, western blot analyses and immunofluorescence detection: monoclonal mouse anti-human CA9 antibody (Abcam, Cambridge, UK); monoclonal rabbit antihuman CA9 antibody (Cell Signaling Technology, Beverly, MA, USA); polyclonal rabbit anti-human E-cadherin antibody (Santa Cruz Biotechnology, Inc., Dallas, TX, USA); monoclonal mouse anti-human N-cadherin antibody (Santa Cruz Biotechnology); polyclonal rabbit anti-human Twist antibody (Santa Cruz Biotechnology); and monoclonal rabbit antihuman ZEB1 antibody (Cell Signaling Technology).

Hypoxic conditions. For treatments with hypoxia, cells were maintained in a humidified incubator with $1 \% \mathrm{O}_{2}, 5 \% \mathrm{CO}_{2}$ and $94 \% \mathrm{~N}_{2}$. For chemically-induced hypoxia, $\mathrm{CoCl}_{2}$ was added to the medium at $200 \mu \mathrm{M}$. Cells cultured under normoxic conditions were used as the control.

Transfection of small interfering RNA (siRNA). Small interfering RNAs that targeted CA9 (siRNA-CA9) was purchased from Invitrogen (Waltham, MA, USA). The siRNA-CA9 sequences were: 5'-GGAAGAAAACAGUGCCUAUtt-3' and 5'-AUAGGCACUGUUUUCUUCCgg-3'. Cells were transfected with $40 \mu \mathrm{mol} / 1$ siRNA and RNAiMAX (Invitrogen). After an overnight incubation, cells were incubated in normoxia or hypoxia. Mock-transfected cells were used as a negative control.

Patients and tumor samples. From 2000 to 2010, 117 patients (92 men, 25 women, aged 36-84 years) with primary HCC underwent hepatectomies at the Osaka University Hospital. These patients had no history of transcatheter arterial chemoembolization (TACE), and they underwent radical surgery without macroscopic residual tumors. Surgical specimens were fixed in $10 \%$ buffered formalin, embedded in paraffin, and stained with hematoxylin-eosin for histological evaluation.

Cell viability assay. Cell viability was analyzed with the methyl tetrazolium (MTT) assay. Briefly, cells treated with siRNA-CA9 or mock control were seeded at $5 \times 10^{3}$ cells/well in 96-well plates. The MTT assay was performed at 24 and $48 \mathrm{~h}$. For the assay, $10 \mu \mathrm{l}$ of $5 \mathrm{mg} / \mathrm{ml}$ MTT (Invitrogen) was added to each well, and cells were incubated for $4 \mathrm{~h}$; then, $100 \mu \mathrm{l}$ dimethyl sulfoxide (DMSO) was added. After the MTT crystals were completely dissolved, the absorbance of each well was measured at $490 \mathrm{~nm}$ with a microplate reader (Bio-Rad Laboratories, Inc., Hercules, CA, USA).

Reverse transcription polymerase chain reaction analysis. Complementary DNA (cDNA) was generated from $1 \mu \mathrm{g}$ RNA with avian myeloblastosis virus reverse transcriptase (Promega, Madison, WI, USA). Quantitative reverse transcription polymerase chain reaction (qRT-PCR) analyses were performed with the LightCycler and detection system (Roche Diagnostics GmbH, Mannheim, Germany) as previously described (24). Gene expression was measured in duplicate. The PCR conditions for CA9, E-cadherin, N-cadherin and vimentin amplifications were: one denaturing cycle at $95^{\circ} \mathrm{C}$ for $10 \mathrm{~min}$, followed by 45 cycles of: $95^{\circ} \mathrm{C}$ for $15 \mathrm{sec}$, a suitable annealing temperature for $10 \mathrm{sec}, 72^{\circ} \mathrm{C}$ for $30 \mathrm{sec}$ and a final extension at $72^{\circ} \mathrm{C}$ for $10 \mathrm{~min}$. The annealing temperatures for CA9, E-cadherin, N-cadherin and vimentin were 67, 64, 62 and $62^{\circ} \mathrm{C}$, respectively. The housekeeping gene, beta actin ( $\beta$-actin), was quantitatively amplified concurrently to verify the integrity of the RNA. The primer sequences were as follows: CA9 forward primer, 5'-GATGAGAAGGCAGCAC AGAAGG-3' and CA9 reverse primer, 5'-CTCTGGCTGG CTTCTCACATTC-3'; E-cadherin forward primer, 5'-GAGA AACAGGATGGCTGAAGG-3' and E-cadherin reverse primer, 5'-TGAGGATGGTGTAAGCGATGG-3'; N-cadherin forward primer, 5'-TGTTGACTATGAAGGCAGTGG-3' and $\mathrm{N}$-cadherin reverse primer, 5'-TCAGTCATCACCTCCAC CAT-3'; vimentin forward primer, 5'-AGCTAACCAACGAC AAAGCC-3' and vimentin reverse primer, 5'-TCCACTTTGC GTTCAAGGTC-3'; $\beta$-actin forward primer, 5'-GGCGGCAC CCCATGTACCCT-3' and $\beta$-actin reverse primer, 5'-AGGGG CCGGACTCGTCATACT-3'.

Western blot analysis. Western blotting was performed as previously described (25). Briefly, cell cultures were lysed with RIPA Buffer (Thermo Fisher Scientific, Inc., Rockford, IL, USA), according to the manufacturer's protocol. Aliquots $(15 \mu \mathrm{g})$ of proteins were electrophoresed on sodium dodecyl sulfate-polyacrylamide gels containing $10 \%$ Tris- $\mathrm{HCl}$ 
(Bio-Rad Laboratories). The separated proteins were transferred to polyvinylidene difluoride membranes and incubated with primary antibodies overnight at $4^{\circ} \mathrm{C}$.

Immunofluorescence staining. For immunofluorescence staining, cells were seeded on 12 -well plates and stained according to procedures previously described (25). Briefly, cells were fixed in $4 \%$ paraformaldehyde for $15 \mathrm{~min}$ and permeabilized with $0.1 \%$ Triton X-100 in phosphate-buffered saline (PBS) for $10 \mathrm{~min}$. Then, the cells were incubated with anti-human CA9, anti-human E-cadherin, or anti-human $\mathrm{N}$-cadherin antibodies overnight at $4^{\circ} \mathrm{C}$. After washing, the cells were further incubated with Alexa Fluor 488 goat antirabbit IgG (Invitrogen) or Alexa Fluor 546 goat anti-mouse $\mathrm{IgG}$ (Invitrogen) for $30 \mathrm{~min}$ at room temperature. Finally, the cells were washed and incubated with Hoechst staining solution for $3 \mathrm{~min}$. Preparations were analyzed with fluorescence microscopy (Keyence Corp., Osaka, Japan).

Immunohistochemistry. Immunohistochemical staining was performed to determine CA9 expression in samples resected from patients with HCC. Briefly, formalin-fixed, paraffinembedded, $4-\mu \mathrm{m}$ thick sections were deparaffinized, then treated with an antigen retrieval procedure. Sections were incubated in methanol containing $0.3 \%$ hydrogen peroxide to block endogenous peroxidase. Sections were then incubated with a normal protein-blocking serum solution and a biotin-blocking solution (Vector Laboratories, Burlingame, CA, USA), as recommended by the manufacturer. Next, the sections were incubated overnight at $4^{\circ} \mathrm{C}$ with a mouse monoclonal anti-human CA9 antibody (Abcam; 1:200). After washing in PBS, the sections were incubated with biotinconjugated secondary antibody (horse anti-mouse $\operatorname{IgG}$ ) and with peroxidase-conjugated streptavidin. The peroxidase reaction was then developed with $0.02 \%$ of 3,30-diaminobenzidine tetrachloride (Wako Pure Chemical Industries, Ltd., Osaka, Japan) solution with $0.03 \%$ hydrogen peroxidase. Finally, the sections were counter-stained with Meyer's hematoxylin. Negative control sections were treated the same, except that the primary antibody was replaced with Tris-buffered saline.

Evaluation of immunohistochemistry. Immunohistochemically stained sections were evaluated independently by two investigators; both were unaware of the clinical data. The sections were first scanned with light microscopy at low magnification (x40); then, all fields were examined at a final magnification of $\mathrm{x} 400$. Results were expressed as the percentage of positively stained cells (a) and the staining intensity (b). The percentage of positively stained cells was graded as follows: 0 (no staining), 1 ( $\leq 10 \%$ of cells stained), 2 (11-50\% of cells stained), 3 (51-75\% of cells stained), or 4 ( $>75 \%$ of cells stained). The staining intensity was scored as follows: 0 (no staining), 1 (weaker than the positive control), or 2 (equal to the positive control; Fig. 7Aa-c). The immunoreactivity score (IRS) was calculated as follows: IRS $=a \times b$, range $0-8$. Tumors with IRS values of 0-1 were considered CA9-negative and tumors with IRS scores of 2-8 were considered CA9-positive.

Statistical analysis. Data from in vitro experiments and all clinicopathological indicators were compared with the
Fisher's exact test. Continuous variables were compared with the Student's t-test. Survival curves were calculated with the Kaplan-Meier method, and differences between the survival curves were compared with the log-rank test. To evaluate the risk associated with prognostic variables, we applied the Cox model to determine the hazard ratio and the $95 \%$ confidence interval (95\% CI). All statistical analyses were performed with the statistical software JMP, version 11 (SAS Institute, Inc., Cary, NC, USA). Two-sided $\mathrm{P}<0.05$ were considered statistically significant.

\section{Results}

Expression of CA9 under hypoxic conditions in HCC cells. First, we evaluated whether CA9 was induced under hypoxic conditions in HCC cell lines. CA9 gene expression in $\mathrm{HuH} 7$ cells was approximately four times higher than that in HepG2 cells under normoxia. CA9 gene expression increased after $24 \mathrm{~h}$ of exposure to $1 \%$ oxygen in both $\mathrm{HuH} 7$ and HepG2 cells (Fig. 1A). CA9 protein levels also increased under hypoxic conditions after $24 \mathrm{~h}$ in both cell lines (Fig. 2). We used $\mathrm{CoCl}_{2}$, a chemical inducer of HIF-1 $\alpha$, to mimic hypoxic conditions in vitro. In $\mathrm{HuH} 7$ cells, CA9 gene expression increased within $48 \mathrm{~h}$ of exposure to $\mathrm{CoCl}_{2}$. In HepG2 cells, CA9 gene expression significantly increased within $24 \mathrm{~h}$ of exposure to $\mathrm{CoCl}_{2}$ (Fig. 3A).

Morphological changes and E-cadherin and $N$-cadherin expression in hypoxia. Next, we examined cells for morphological changes and determined whether EMT marker expression was altered in hypoxic conditions. We found that both $\mathrm{HuH} 7$ and HepG2 cells became spindle-shaped after $72 \mathrm{~h}$ of hypoxia (Fig. 4B). Moreover, under hypoxic conditions, the relative mRNA levels indicated a decrease in the expression of E-cadherin, which plays a pivotal role in the behavior of cells on epithelium, and an increase in $\mathrm{N}$-cadherin expression. We also evaluated the expression of vimentin under hypoxia. Vimentin gene expression increased under hypoxia in both $\mathrm{HuH} 7$ and HepG2 cells although the difference was not significant in HepG2 cells (Fig. 1B). Western blot analyses also revealed that hypoxia downregulated the expression of E-cadherin and upregulated the expression of Twist, a transcriptional regulator of the EMT (Fig. 2).

We then investigated whether $\mathrm{CoCl}_{2}$ treatment altered the expression of E-cadherin and $\mathrm{N}$-cadherin. After $48 \mathrm{~h}$ of exposure to conditions that mimicked hypoxia, both $\mathrm{HuH} 7$ and HepG2 cells showed relative reductions in E-cadherin mRNA levels and relative increases in N-cadherin mRNA levels (Fig. 3B). Immunofluorescence staining showed that E-cadherin was expressed on the membranes of cells, and that CA9 was not expressed in normoxic conditions. After exposing the cells to conditions that mimicked hypoxia, CA9 expression increased on cell membranes and in the cytoplasm, E-cadherin expression was lost and $\mathrm{N}$-cadherin expression was gained (Fig. 4A). Thus, we confirmed that both hypoxia and exposure to $\mathrm{CoCl}_{2}$ caused CA9 induction and E-cadherin repression.

siRNA-mediated knockdown of CA9: influence on cell growth. To clarify the effects of CA9 on cell growth, we performed a 
A

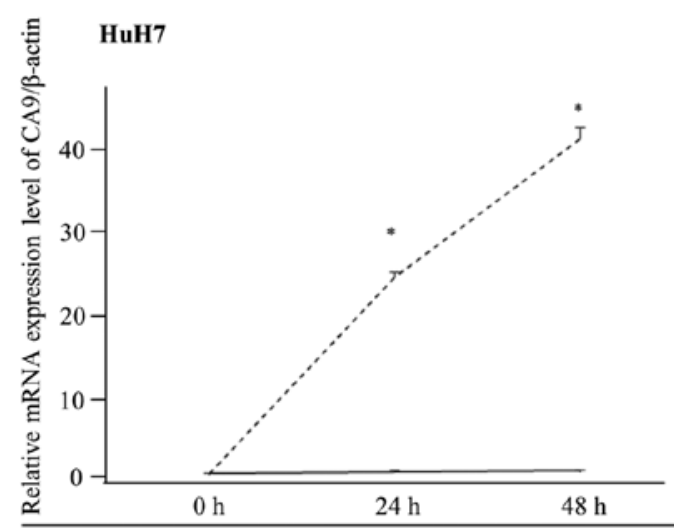

B

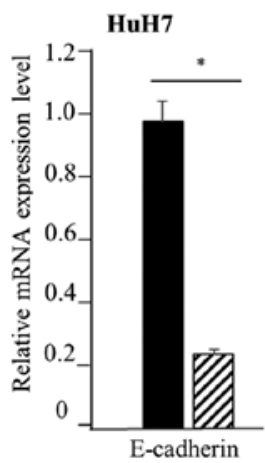

Normoxia ${ }^{*} p<0.01$

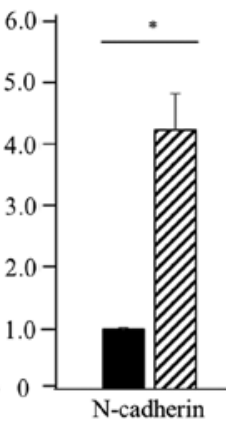

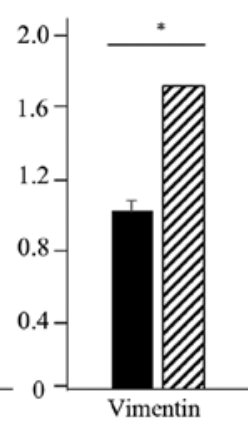

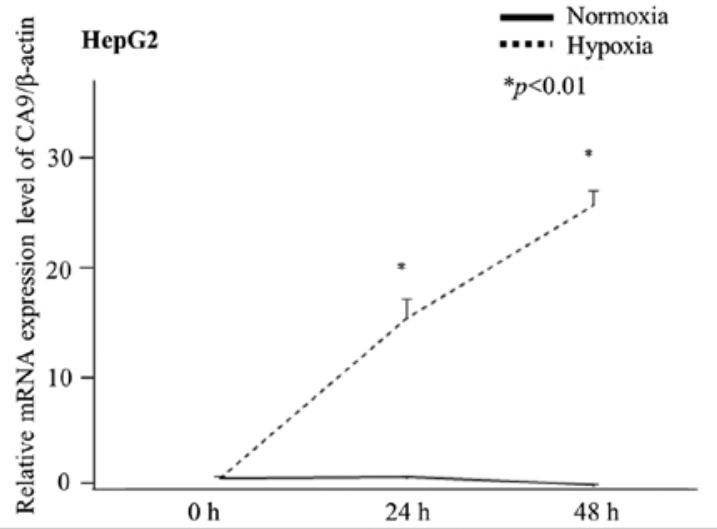

HepG2

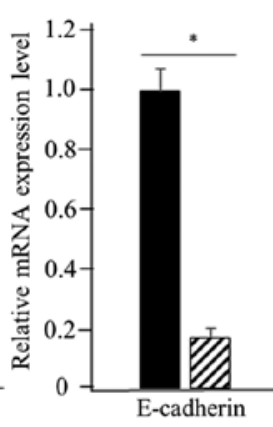

E-cadherin

Figure 1. Hypoxia alters CA9, E-cadherin and N-cadherin gene expression. (A) Hypoxia significantly induced gene CA9 expression at 24 and 48 h in both $\mathrm{HuH} 7$ and HepG2 cell lines. (B) Hypoxia significantly decreased E-cadherin expression and significantly increased N-cadherin expression in HuH7 and HepG2 cells. Vimentin gene expression also significantly increased under hypoxia in HuH7 cells although there was no significant difference in HepG2 cells. ${ }^{*} \mathrm{P}<0.01$ vs. normoxia.

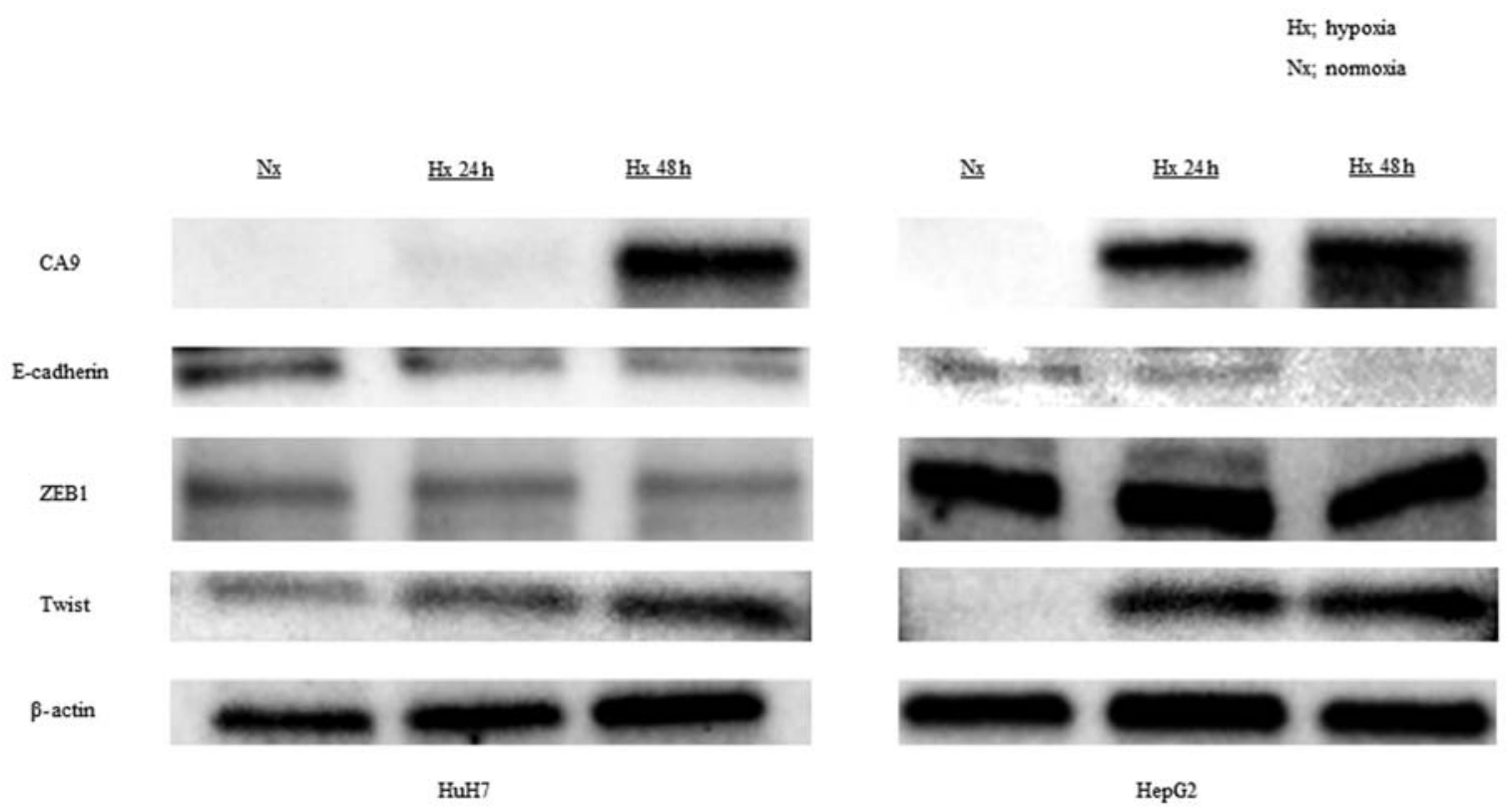

Figure 2. Hypoxia effects on CA9, E-cadherin, ZEB1 and Twist protein expression in HCC cells. Western blot analyses of HuH7 and HepG2 cells show that CA9 expression increased with hypoxia (Hx) compared to normoxia (Nx). Twist expression also increased with hypoxia (Hx), however, E-cadherin expression decreased with hypoxia, compared to normoxia $(\mathrm{Nx})$.

knockdown of CA9 with a CA9-specific siRNA. Transfection of CA9 siRNA into HuH7 and HepG2 cells repressed the CA9 mRNA level to $<20 \%$ of the control (mock-transfected). Under normoxic conditions, HuH7 cells with the CA9 knockdown showed no significant difference in relative cell viability compared to controls. However, in HepG2 cells, the CA9 


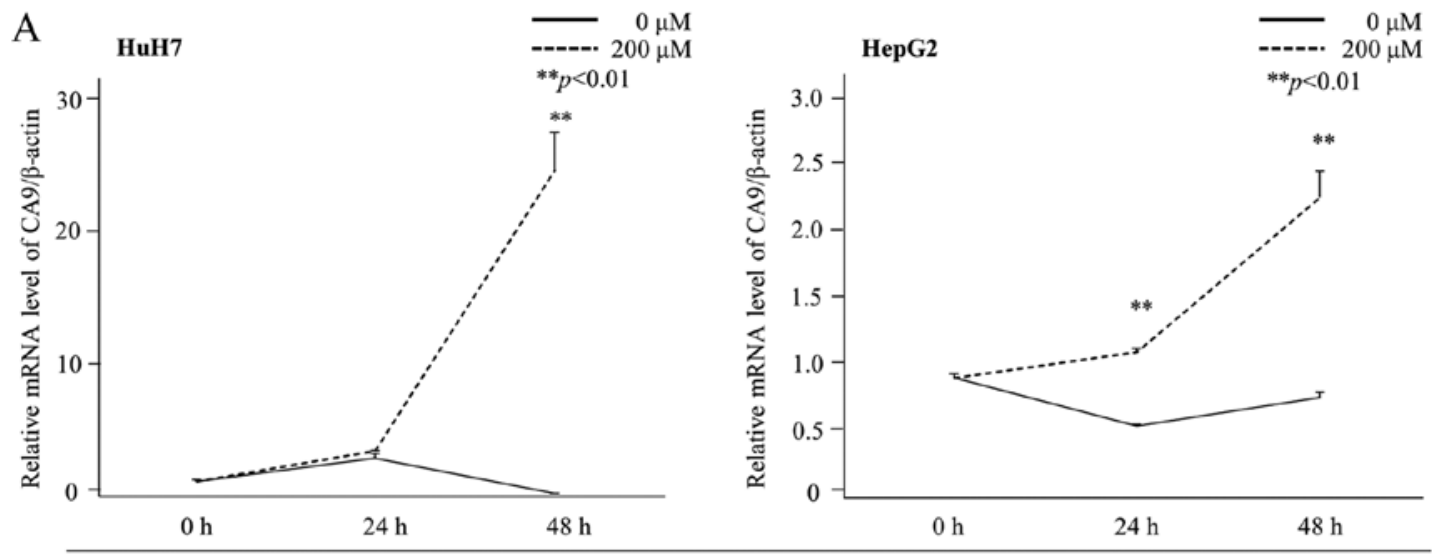

B $\quad \mathrm{HuH7}$
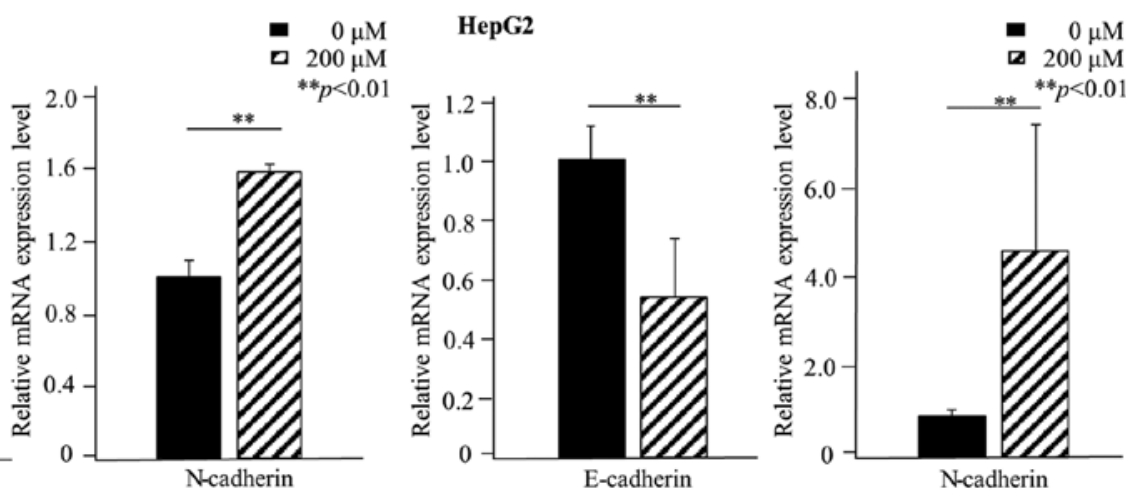

Figure 3. Hypoxia mimicked with $\mathrm{CoCl}_{2}$ altered the expression of $\mathrm{CA} 9$, E-cadherin and $\mathrm{N}$-cadherin genes. $\mathrm{CoCl}_{2}$ was used to mimic hypoxic conditions (A) With $\mathrm{CoCl}_{2}, \mathrm{CA} 9$ expression significantly increased at $48 \mathrm{~h}$ in both $\mathrm{HuH} 7$ and $\mathrm{HepG} 2$ cells. (B) With $\mathrm{CoCl}_{2}, \mathrm{E}-$ cadherin expression significantly decreased and $\mathrm{N}$-cadherin expression significantly increased in both $\mathrm{HuH} 7$ and $\mathrm{HepG} 2$ cells. ${ }^{*} \mathrm{P}<0.01$ vs. no $\mathrm{CoCl}_{2}$.
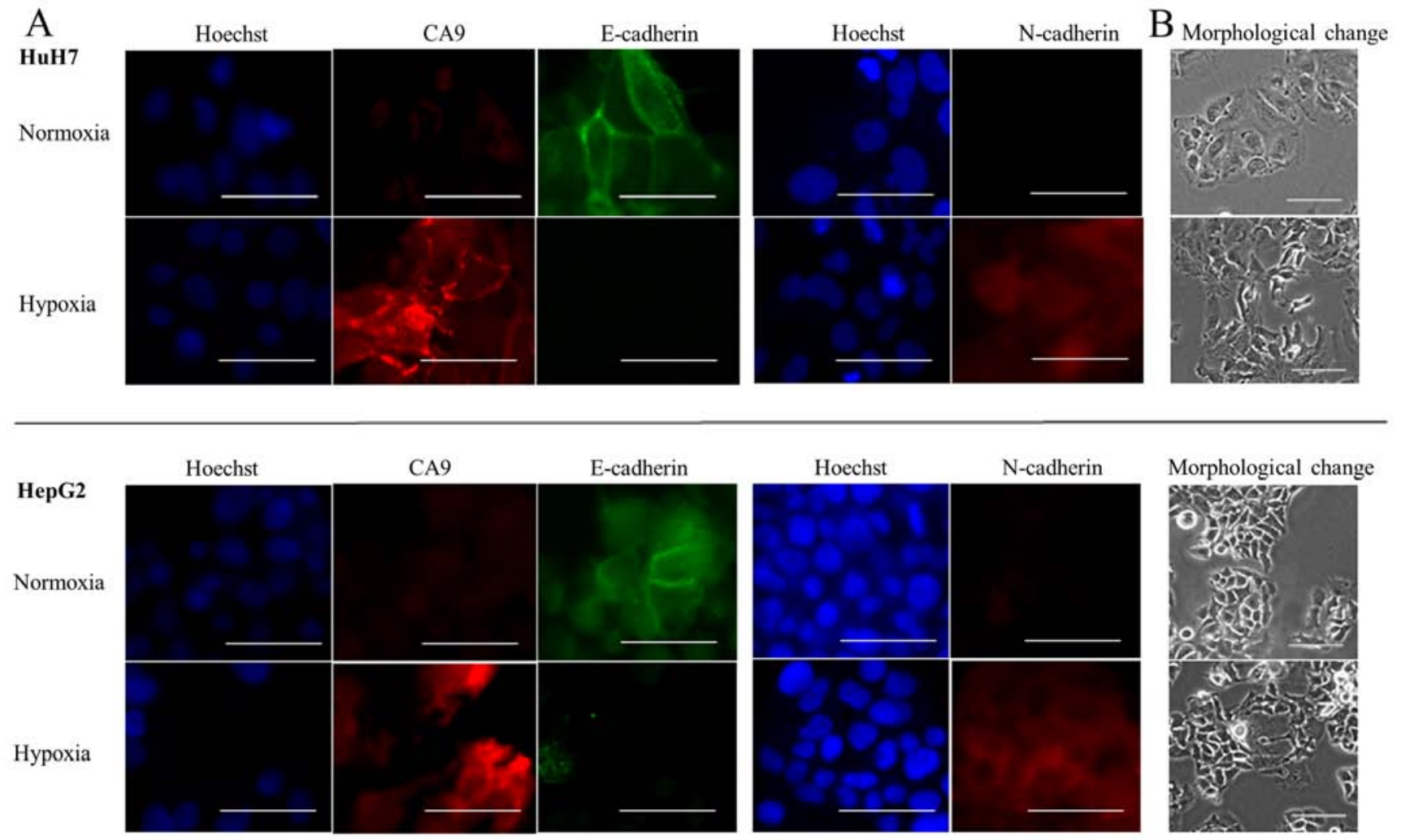

Figure 4. Hypoxia altered protein expression and morphological changes in HCC cells. (A) Immunofluorescence staining shows protein expression of CA9 (red), E-cadherin (green) and N-cadherin (red) in HuH7 and HepG2 cells. Nuclear staining (blue) was performed with Hoechst. Under hypoxia, CA9 and $\mathrm{N}$-cadherin were upregulated and E-cadherin was downregulated. The scale bars, $50 \mu \mathrm{M}$. (B) Representative cell morphological changes under hypoxia. Hypoxia induced both $\mathrm{HuH} 7$ and $\mathrm{HepG} 2$ cells to become spindle-shaped. The scale bars, $100 \mu \mathrm{M}$. 

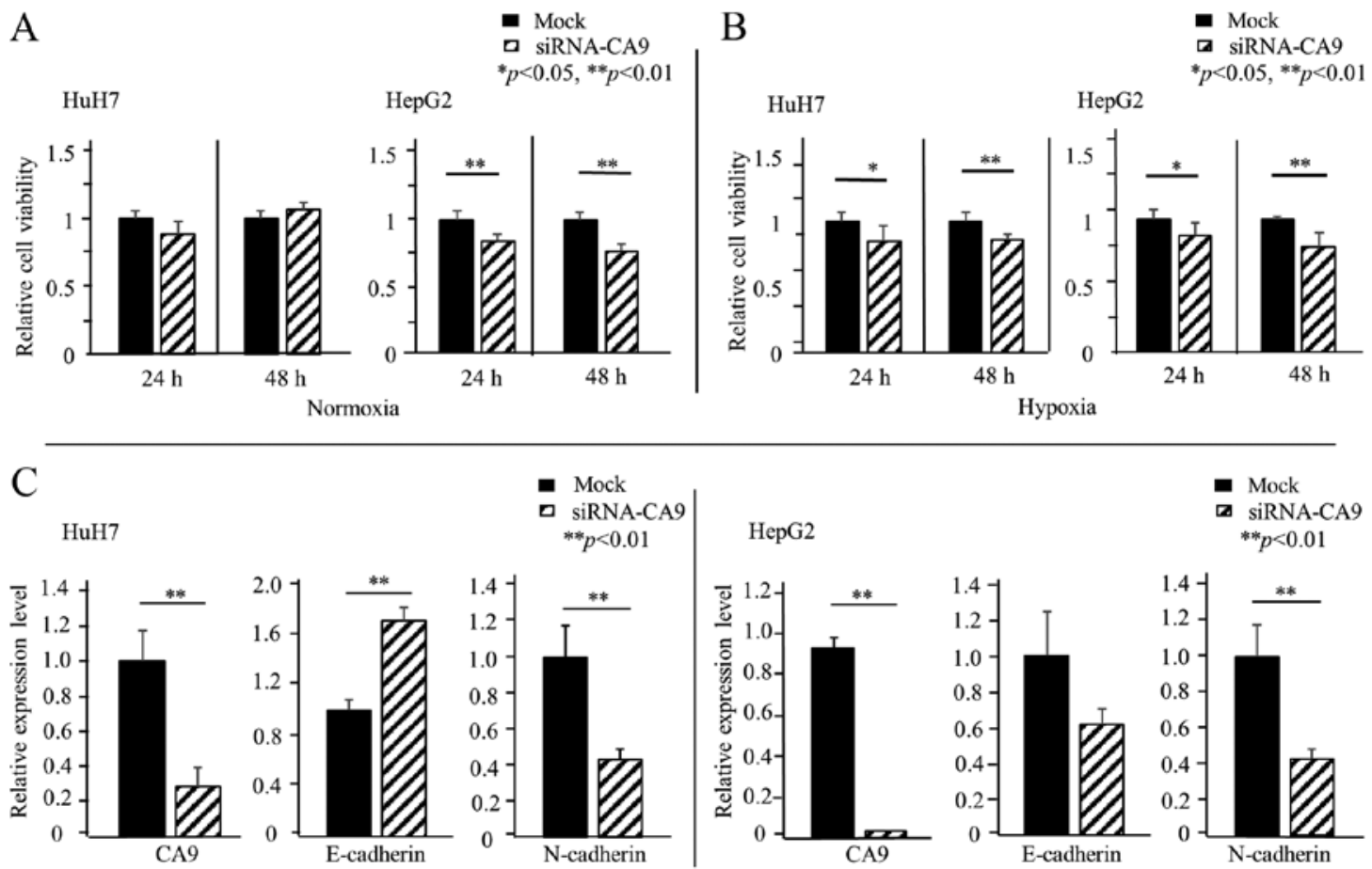

Figure 5. CA9 knockdown affects cell viability and EMT-related molecule expression under hypoxic conditions. MTT assay results show (A) the relative cell viabilities after knocking down CA9 in HuH7 (left panel) and HepG2 (right panel) cells, under normoxic conditions. Relative cell viability was not significantly different between transfected HuH7 cells (striped bars) and controls (black bars). However, the CA9 knockdown repressed relative cell viability in HepG2 cells. " $\mathrm{P}<0.05$ and ${ }^{* *} \mathrm{P}<0.01$ vs. mock-transfected cells. (B) Under hypoxic conditions, the CA9 knockdown repressed relative cell viabilities in both HuH7 and HepG2 cells. ${ }^{*} \mathrm{P}<0.05$ and ${ }^{* *} \mathrm{P}<0.01$ vs. mock-transfected cells. (C) qRT-PCR results show gene expression in hypoxic conditions. (C, left panel) In HuH7 cells, the CA9 knockdown attenuated the hypoxia-induced suppression of E-cadherin and stimulation of N-cadherin gene expression. (C, right panel) In HepG2 cells, the CA9 knockdown did not significantly alter the E-cadherin gene expression, but it attenuated the hypoxia-induced stimulation of $\mathrm{N}$-cadherin gene expression. ${ }^{*} \mathrm{P}<0.01$ vs. mock-transfected cells.

A

Hoechst

CA9

E-cadherin

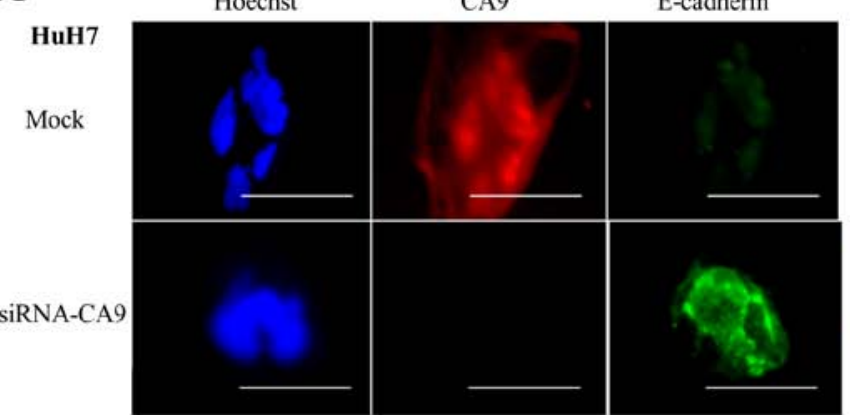

Hoechst

N-cadherin

B Morphological change
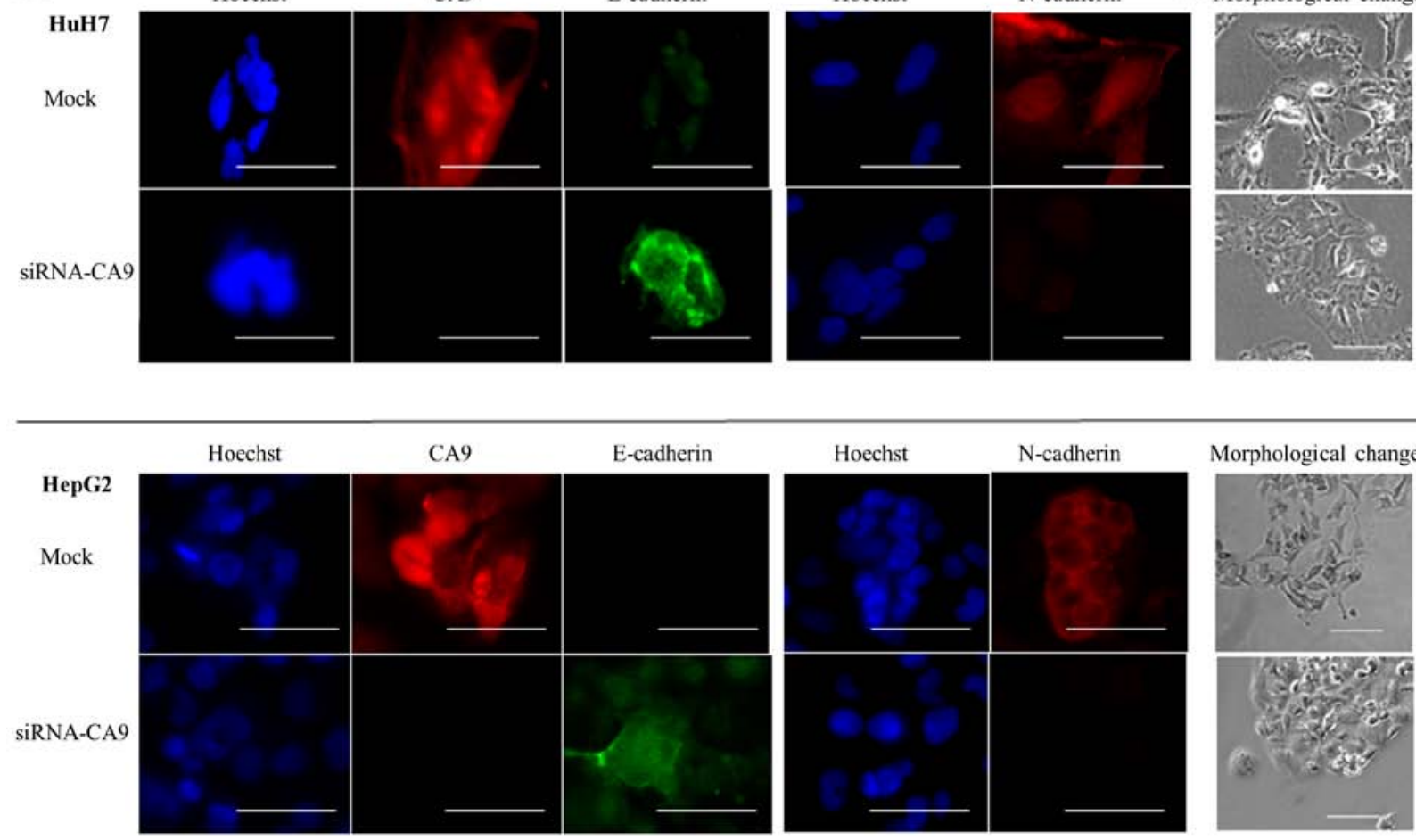

Morphological change

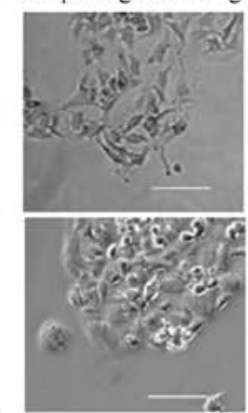

Figure 6. Hypoxia-induced changes in morphology and protein expression were eliminated after knocking down CA9 in HCC cells. (A) Immunofluorescence staining shows expression of CA9 (red), E-cadherin (green) and N-cadherin (red) in cell cultures. Nuclear staining (blue) was performed with Hoechst. (Top rows) Hypoxia induced a downregulation of E-cadherin and an upregulation of N-cadherin, in HuH7 and HepG2 cells. (Bottom rows) The siRNA-CA9 knockdown counteracted the effects of hypoxia. Scale bars, $50 \mu \mathrm{m}$. (B) Representative morphological (spindle-shapes) changes in cells under hypoxia (top panels) were attenuated in both HuH7 and HepG2 CA9-knockdown cells (bottom panels). Scale bars, $100 \mu \mathrm{m}$. 
Table I. Clinicopathological factors of 117 patients with resected hepatocellular carcinoma.

\begin{tabular}{|c|c|c|c|}
\hline Variables & $\mathrm{CA} 9(+)(\mathrm{N}=59)$ & CA9(-) $(\mathrm{N}=58)$ & P-value \\
\hline \multicolumn{4}{|l|}{ Baseline characteristics } \\
\hline Age $(\text { years })^{\mathrm{a}}$ & $68.7 \pm 1.3$ & $66.7 \pm 1.3$ & 0.15 \\
\hline Sex (male/female) & $50 / 9$ & $42 / 16$ & 0.12 \\
\hline HBs-Ag (+/-) & $13 / 49$ & $14 / 44$ & 0.83 \\
\hline Anti-HCV Ab (+/-) & $30 / 29$ & $32 / 26$ & 0.71 \\
\hline Child-Pugh classification (A/B) & $50 / 9$ & $51 / 6$ & 0.58 \\
\hline $\operatorname{AFP}(\mathrm{ng} / \mathrm{ml})^{\mathrm{a}}$ & $7553 \pm 12913$ & $18952 \pm 13024$ & 0.73 \\
\hline PIVKA-II (mAU/ml)a & $4912 \pm 6047$ & $9267 \pm 6099$ & 0.69 \\
\hline \multicolumn{4}{|l|}{ Pathologic characteristics } \\
\hline Tumor size $(\mathrm{cm})^{\mathrm{a}}$ & $3.5 \pm 0.3$ & $3.8 \pm 0.3$ & 0.73 \\
\hline Number of tumors (St/Mt) & $43 / 16$ & $44 / 14$ & 0.83 \\
\hline Macroscopic Vp (+/-) & $8 / 51$ & $5 / 53$ & 0.56 \\
\hline Histological type (well, mod/por) & $30 / 29$ & $26 / 32$ & 0.58 \\
\hline Liver cirrhosis (NL, CH/LC) & $37 / 22$ & $32 / 26$ & 0.84 \\
\hline Microscopic vp (+/-) & $17 / 42$ & $15 / 43$ & 0.83 \\
\hline
\end{tabular}

CA9, carbonic anhydrase-9; (+), (-), positive or negative staining; HBs-Ag, hepatitis B surface antigen; Anti-HCV Ab, anti-hepatitis-C virus antibodies; AFP, $\alpha$-fetoprotein; PIVKA-II, prothrombin induced by vitamin K absence-II; St, Mt, single tumor or multiple tumor; well, mod, por: well differentiated or moderately differentiated; NL, normal liver; $\mathrm{CH}$, chronic hepatitis; LC, liver cirrhosis; Vp, portal vein tumor thrombus at clinical diagnosis; vp, portal vein tumor thrombus at postoperative diagnosis. ${ }^{\text {a }}$ Data were shown as mean \pm standard deviation.

knockdown significantly decreased the relative cell viability in normoxic conditions (Fig. 5A). Under hypoxic conditions, the CA9 knockdown decreased relative cell viabilities in both HuH7 and HepG2 cells (Fig. 5B).

Effect of the CA9 knockdown on hypoxia-induced EMT. In HuH7 and HepG2 cells transfected with siRNA-CA9, we evaluated the expression of E-cadherin and $\mathrm{N}$-cadherin in hypoxic conditions. Both qRT-PCR and immunofluorescence staining results showed that the CA9-knockdown abrogated hypoxia-mediated E-cadherin repression in $\mathrm{HuH} 7$, but not HepG2, cells. The CA9 knockdown also attenuated hypoxia-induced $\mathrm{N}$-cadherin expression in both $\mathrm{HuH} 7$ and HepG2 cells (Figs. 5B and 6A). Moreover, cells with the CA9-knockdown exhibited less spindle-shaped morphology than cells with unaltered CA9 expression (Fig. 6B). These results suggested that knocking down CA9 counteracted hypoxia-induced EMT. Thus, CA9 might regulate hypoxiapromoted EMT.

Correlations between tumor CA9 expression and clinicopathological findings. To elucidate the clinical significance of CA9 expression in HCC, we performed immunohistochemical evaluations of HCC tissue samples acquired from 117 patients that underwent radical surgery. We detected little or no CA9 reactivity in hepatocytes from liver tissue adjacent to the tumor, but we detected moderate to strong CA9 reactivity in the interlobular bile ducts. The expression of CA9 in HCC was heterogeneous and there were no specific areas in which CA9 was overexpressed, such as central lesions or marginal lesions. The IRS evaluations indicated that, of the 117 tumors, 59
(50.4\%) showed positive CA9 staining and 58 (49.6\%) showed negative CA9 staining.

Next, we evaluated correlations between CA9 expression and clinicopathological factors. Table I shows the relationship between immunohistochemical detection of CA9 expression and clinicopathological characteristics of 117 patients with HCC. We found no significant difference in clinicopathological factors between the CA9-positive and CA9-negative groups.

Univariate and multivariate analyses of associations between patient survival and CA9 expression. Fig. 7 shows the diseasefree survival (DFS) and overall survival (OS) after surgery for patients with and without CA9 expression. The CA9-positive group showed significantly shorter DFS and OS, compared to the CA9-negative group. The 1-, 3- and 5-year DFS rates were $62.5,41.7$ and $29.9 \%$, respectively, for patients with positive CA9 expression, and 79.1, 56.3, 43.7\%, respectively, for those with negative CA9 expression $(\mathrm{P}=0.045)$. The 1-, 3- and 5-year OS rates were $96.6,78.2$ and $57.6 \%$ for patients with positive CA9 expression, and 98.3, 94.7 and $94.7 \%$, respectively, for those with negative CA9 expression $(\mathrm{P}=0.0002)$.

We also evaluated the prognostic factors for DFS and OS in univariate and multivariate analyses. The univariate analysis of DFS data revealed several factors that were significantly associated with postoperative recurrence, including serum $\operatorname{AFP}(\mathrm{P}=0.0048)$, number of tumors $(\mathrm{P}=0.0088)$, macroscopic vascular invasion $(\mathrm{P}=0.026)$, liver cirrhosis $(\mathrm{P}=0.026)$, microscopic vascular invasion $(\mathrm{P}=0.0011)$ and $\mathrm{CA} 9$ expression $(\mathrm{P}=0.046)$. The multivariate analysis of DFS data revealed four significant independent prognostic factors, including serum AFP $(\mathrm{P}=0.029)$, liver cirrhosis $(\mathrm{P}=0.009)$, microscopic 
Table II. Factors related to disease-free survival (DFS), based on univariate and multivariate analyses.

\begin{tabular}{|c|c|c|c|c|c|c|}
\hline \multirow[b]{2}{*}{ Variables } & \multicolumn{3}{|c|}{ Univariate } & \multicolumn{3}{|c|}{ Multivariate } \\
\hline & HR & $95 \% \mathrm{CI}$ & P-value & HR & $95 \% \mathrm{CI}$ & P-value \\
\hline Age ( $\geq 70$ vs. $<70$ years) & 2.00 & $6.30-0.50$ & 0.21 & & & \\
\hline Sex (male vs. female) & 1.75 & $0.97-3.43$ & 0.06 & & & \\
\hline HBs-Ag (yes vs. no) & 0.60 & $0.31-1.08$ & 0.09 & & & \\
\hline HCV-Ab (yes vs. no) & 1.54 & $0.96-2.54$ & 0.07 & & & \\
\hline Child-Pugh classification (A vs. B) & 0.86 & $0.45-1.85$ & 0.67 & & & \\
\hline AFP ( $\geq 20$ vs. $<20 \mathrm{ng} / \mathrm{ml}$ ) & 1.97 & $1.23-3.17$ & $<0.01$ & 1.99 & $1.19-3.39$ & $<0.01$ \\
\hline PIVKA-II ( $\geq 100$ vs. $<100 \mathrm{U} / \mathrm{ml}$ ) & 1.59 & $0.99-2.60$ & 0.06 & & & \\
\hline Tumor size ( $\geq 20$ vs. $<20 \mathrm{~mm}$ ) & 1.10 & $0.95-12.7$ & 0.06 & & & \\
\hline Number of tumors (St vs. Mt) & 0.49 & $0.30-0.83$ & $<0.01$ & 0.92 & $0.52-1.65$ & 0.76 \\
\hline Macroscopic Vp (yes vs. no) & 2.44 & $1.12-4.73$ & $\mathbf{0 . 0 3}$ & & & \\
\hline Histological type (well, mod/por) & 0.68 & $0.42-1.09$ & 0.11 & & & \\
\hline Liver cirrhosis (NL+CH vs. $\mathrm{LC}$ ) & 0.58 & $0.36-0.94$ & $\mathbf{0 . 0 3}$ & 0.51 & $0.30-0.85$ & $<0.01$ \\
\hline Microscopic vp (yes vs. no) & 2.53 & $1.47-4.23$ & $<0.01$ & 2.19 & $1.25-3.77$ & $<0.01$ \\
\hline CA9 (positive vs. negative) & 1.63 & $1.01-2.64$ & 0.05 & 1.18 & $1.07-2.96$ & 0.03 \\
\hline
\end{tabular}

HR, hazard ratio; CI, confidence interval; HBs-Ag, hepatitis B surface antigen; Anti-HCV Ab, anti-hepatitis-C virus antibodies; AFP, $\alpha$-fetoprotein; PIVKA-II, prothrombin induced by vitamin K absence-II; St, Mt, single tumor or multiple tumor; well, mod, por, well differentiated or moderately differentiated, poorly differentiated; NL, normal liver; $\mathrm{CH}$, chronic hepatitis; LC, liver cirrhosis; Vp, portal vein tumor thrombus at clinical diagnosis; vp, portal vein tumor thrombus at postoperative diagnosis; CA9, carbonic anhydrase-9; positive or negative, immunohistochemical staining result. Bold, statistically significant.

Table III. Factors related to overall survival (OS), based on univariate and multivariate analyses.

\begin{tabular}{|c|c|c|c|c|c|c|}
\hline \multirow[b]{2}{*}{ Variables } & \multicolumn{3}{|c|}{ Univariate } & \multicolumn{3}{|c|}{ Multivariate } \\
\hline & HR & $95 \% \mathrm{CI}$ & P-value & HR & $95 \% \mathrm{CI}$ & P-value \\
\hline Age ( $\geq 70$ vs. $<70$ years) & 0.97 & $0.39-2.19$ & 0.94 & & & \\
\hline Sex (male vs. female) & 1.83 & $0.69-6.28$ & 0.24 & & & \\
\hline HBs-Ag (yes vs. no) & 0.44 & $0.10-1.28$ & 0.14 & & & \\
\hline HCV-Ab (yes vs. no) & 2.57 & $1.08-7.05$ & 0.03 & 2.48 & $1.02-6.92$ & 0.05 \\
\hline Child-Pugh classification (A vs. B) & 0.61 & $0.48-4.35$ & 0.39 & & & \\
\hline $\operatorname{AFP}(\geq 20$ vs. $<20 \mathrm{ng} / \mathrm{ml}$ ) & 2.63 & $1.17-6.44$ & 0.02 & 1.59 & $0.62-4.35$ & 0.34 \\
\hline PIVKA-II ( $\geq 100$ vs. $<100 \mathrm{U} / \mathrm{ml}$ ) & 2.35 & $1.02-6.05$ & 0.04 & 1.42 & $0.53-4.10$ & 0.50 \\
\hline Tumor size ( $\geq 20$ vs. $<20 \mathrm{~mm}$ ) & 1.61 & $0.56-6.81$ & 0.41 & & & \\
\hline Number of tumor (St vs. Mt) & 0.58 & $0.26-1.41$ & 0.22 & & & \\
\hline Macroscopic Vp (yes vs. no) & 4.28 & $1.55-10.2$ & $<0.01$ & & & \\
\hline Histological type (well, mod/por) & 0.49 & $0.21-1.08$ & 0.08 & & & \\
\hline Liver cirrhosis (NL+CH vs. LC) & 0.54 & $0.24-1.19$ & 0.13 & & & \\
\hline Microscopic vp (yes vs. no) & 3.29 & $1.44-7.31$ & $<0.01$ & 3.29 & $1.30-8.44$ & 0.01 \\
\hline CA9 (positive vs. negative) & 4.79 & $2.34-12.6$ & $<0.01$ & 5.84 & $2.36-16.2$ & $<0.01$ \\
\hline
\end{tabular}

HR, hazard ratio; CI, confidence interval; HBs-Ag, hepatitis B surface antigen; Anti-HCV Ab, anti-hepatitis-C virus antibodies; AFP, $\alpha$-fetoprotein; PIVKA-II, prothrombin induced by vitamin K absence-II; St, Mt, single tumor or multiple tumor; well, mod, por, well differentiated or moderately differentiated, poorly differentiated; NL, normal liver; $\mathrm{CH}$, chronic hepatitis; LC, liver cirrhosis; $\mathrm{Vp}$, portal vein tumor thrombus at clinical diagnosis; vp, portal vein tumor thrombus at postoperative diagnosis; CA9, carbonic anhydrase-9; positive or negative, immunohistochemical staining result. Bold, statistically significant.

vascular invasion $(\mathrm{P}=0.018)$, and $\mathrm{CA} 9$ expression $(\mathrm{P}=0.02$; Table II).
Univariate analyses of OS data showed several factors that were significantly associated with postoperative survival, 
A a
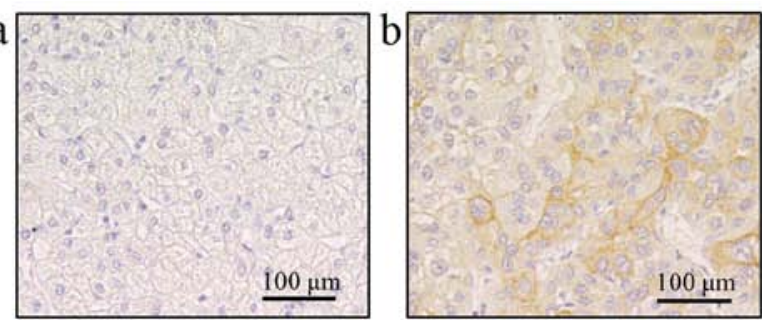

B

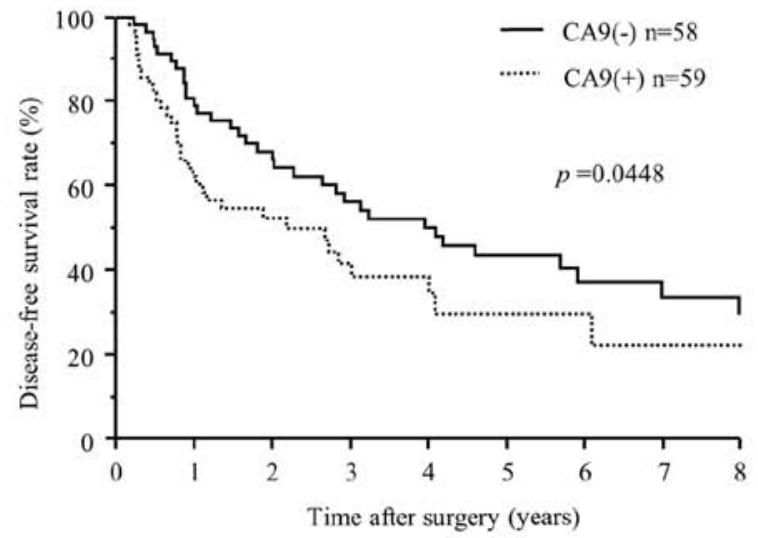

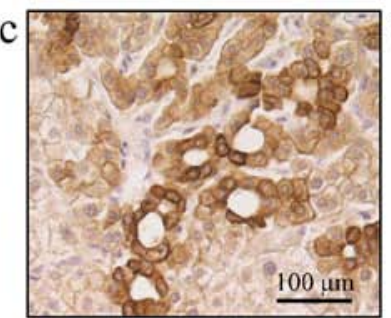
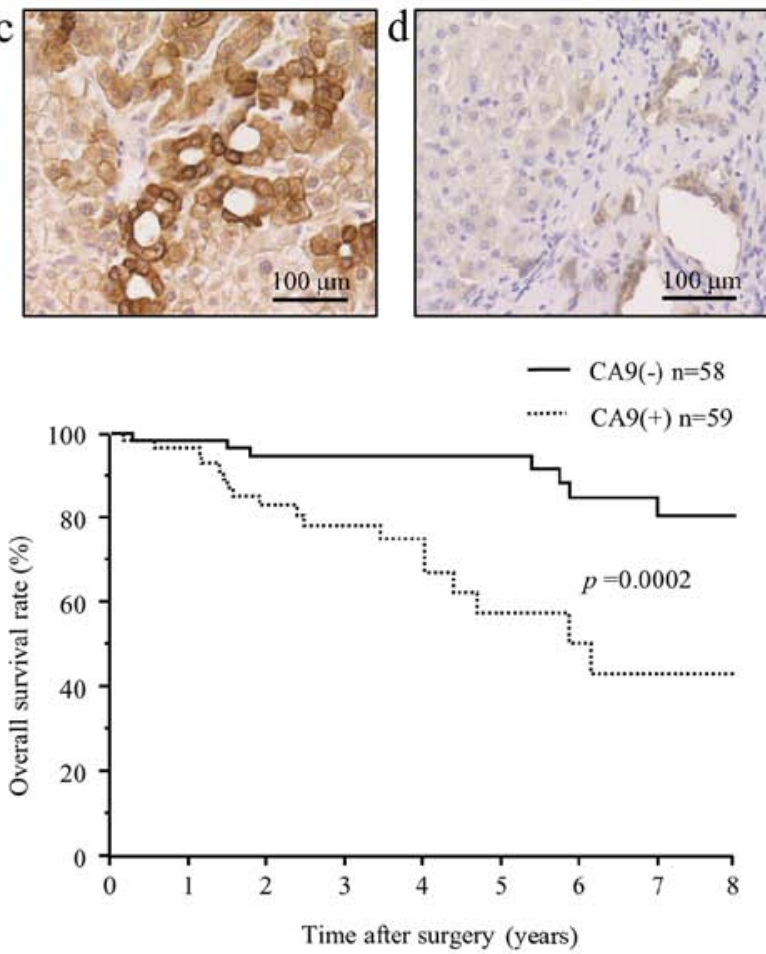

Figure 7. Immunohistochemical expression and clinical significance of CA9 in hepatocellular carcinoma. (A) Immunohistochemical staining of CA9 in cancer cells and adjacent non-cancerous liver tissue. Representative images show different CA9 tissue expression levels, with intensity scores of: (top left, a) 0 , no staining, (top right, b) 1, weak staining, and (bottom left, c) 2, strong staining. (Bottom right, d) CA9 was rarely expressed in normal liver parenchyma, but strong expression was detected in intrahepatic bile ducts. Scale bars, $100 \mu \mathrm{m}$. (B) Kaplan-Meier disease-free survival curve (top) and overall survival curve (bottom) of patients with CA9-positive tumors (dotted lines) or CA9-negative tumors (solid lines). The CA9-positive group showed significantly shorter disease-free survival $(\mathrm{P}=0.0448)$ and overall survival $(\mathrm{P}=0.0002)$ than the $\mathrm{CA} 9$-negative group.

including HCV infection $(\mathrm{P}=0.037)$, serum AFP $(\mathrm{P}=0.019)$, serum PIVKA-II $(\mathrm{P}=0.044)$, macroscopic vascular invasion $(\mathrm{P}=0.007)$, microscopic vascular invasion $(\mathrm{P}=0.005)$ and $\mathrm{CA} 9$ expression $(\mathrm{P}=0.0003)$. The multivariate analysis of OS data revealed three significant independent prognostic factors, including $\mathrm{HCV}$ infection $(\mathrm{P}=0.05)$, microscopic vascular invasion $(\mathrm{P}=0.011)$ and CA9 expression $(\mathrm{P}<0.001$; Table III $)$.

\section{Discussion}

Under hypoxic conditions, a number of chemical substances are induced intracellularly in cancer cells, which facilitate survival in harsh environments. These substances play crucial roles in the invasiveness, metastasis, and growth of cells. Generally, hypoxic stimuli induce the expression of HIF1 $\alpha$, a key molecule in $\mathrm{O}_{2}$ homeostasis (26). HIF1 $\alpha$ stimulates the production of hypoxia-related molecules, such as GLUT1, VEGF and CA9 (27-29). Among these molecules, CA9 is a hypoxia-associated endogenous enzyme that mainly regulates intracellular and extracellular $\mathrm{pH}$ levels.

In the present study, we first evaluated the expression of CA9 under hypoxic conditions in two HCC cell lines, HuH7 and HepG2. We showed that CA9 mRNA and protein levels gradually increased after exposure to hypoxia, in both $\mathrm{HuH} 7$ and HepG2 cells. We also confirmed upregulation of CA9 under pseudo-hypoxic conditions, with $\mathrm{CoCl}_{2}$, which induces conditions that mimic hypoxia by stabilizing HIF1 $\alpha$ (30). These results were consistent with the results previously reported (31).
Next, we examined whether hypoxic conditions induced the EMT phenotype in HCC cell lines. We found that hypoxia and $\mathrm{CoCl}_{2}$-mediated pseudo-hypoxia promoted EMT and regulated EMT, by promoting the transcription factor, Twist, in HCC cell lines. Several previous reports have shown that hypoxia could induce the EMT phenotype via upregulation of HIF1 expression (32,33). In HCC, Zhang et al (34) showed that hypoxia upregulated HIF1, which activated Snail; subsequently, this pathway resulted in E-cadherin depletion and N-cadherin augmentation. Several reports have also revealed that hypoxia upregulated transcription factors that promoted EMT, such as Twist, ZEB1 and Slug, in various tumor cells (34-36).

Many studies have shown that upregulation of CA9 under hypoxic conditions was correlated with cell survival and growth. However, the mechanism underlying the upregulation of CA9 and its contribution to survival and growth of tumor cells had not been fully clarified. CA9 catalyzes the reversible hydration of carbon dioxide into bicarbonate and protons; this conversion allows cells to thrive under hypoxic conditions (10,37). On the other hand, Yu et al (38) reported that CA9 expression inhibited hexokinase II inhibitor-induced apoptosis, and Lock et al (39) showed that CA9 was critical for hypoxia-mediated cancer stem cell expansion in breast cancer cells.

In this study, we conducted MTT assays to evaluate cell survival after the CA9 knockdown. In HuH7 cells, the CA9 knockdown did not affect the relative rate of cell survival in normoxia; however, the CA9 knockdown significantly reduced the relative cell survival rate under hypoxic conditions. In 
HepG2 cells, the CA9 knockdown significantly reduced the relative cell survival rate compared to controls, under both normoxic and hypoxic conditions. Based on these results, we speculated that $\mathrm{HuH} 7$ cell survival might not depend on CA9 expression under normoxic conditions, because $\mathrm{HuH} 7$ expressed little or no CA9 in normoxia. On the other hand, HepG2 cell survival may depend on CA9 expression under both hypoxic and normoxic conditions.

Our results showed that a CA9 knockdown with siRNA attenuated the hypoxia-induced loss of E-cadherin and augmentation of N-cadherin. This counter-effect was confirmed with both genetic and protein analyses in $\mathrm{HuH7}$ cells, and with the protein analysis in HepG2 cells. Furthermore, morphological evaluations showed that the CA9 knockdown also attenuated the tendency of both HuH7 and HepG2 cells to become spindle-shaped in hypoxia. Recent studies have proposed that CA9 participated in tumor microenvironment acidification and the loss of tumor cell-to-cell adhesion. Generally, E-cadherin instability drives the EMT, because E-cadherin plays a central role in cell-to-cell adhesion junctions (40). Previous studies have proposed a few mechanisms that might contribute to the loss of cell-to-cell adhesion with CA9 upregulation. One hypothesis held that CA9 expression inhibited or competed against adapter molecules, such as $\beta$-catenin and $\alpha$-catenin, at adherent junctions. This interaction could disturb connections between adapter molecules and the intracellular domain of E-cadherin, which could lead to E-cadherin instability (23).

Lock et al (39) showed that hypoxia-induced CA9 could regulate Snail, a transcription factor that promotes EMT, in the stem cell compartment of breast cancer cells. They also hypothesized that CA9 expression might regulate EMT through a potential mechanism involving mTORC1 signaling. Other transcription factors that promote EMT include ZEB1, ZEB2, Slug and Twist (41-44). In this study, we found that Twist displayed upregulated expression under hypoxic conditions. Further investigation is necessary to reveal the correlation between CA9 and mTORC1 signaling in HCC. We thought these two pathways were main mechanisms in the regulation of EMT by CA9.

In HuH7 cells, CA9 regulated E-cadherin transcription. On the other hand, in HepG2 cells, a CA9 knockdown did not affect E-cadherin transcription. These results suggested that the two cell lines might employ different mechanisms for regulating EMT via CA9. For example, CA9 may drive E-cadherin instability at the post-transcriptional level in HepG2 cells.

We also investigated the clinical and pathological significance of CA9 expression in 117 patients with HCC. The rate of CA9-positive staining was 50.4\% (59/117) but there was no significant difference between the CA9(+) and CA9(-) groups in clinicopathological factors. A previous study showed a $15 \%$ rate of CA9-positive staining in HCC samples. However, that study included only 17 immunohistochemically-stained HCC samples. Another study showed a $21.5 \%$ rate of CA9-positive staining. That study included patients that were preoperatively treated with TACE and radiofrequency ablation (RFA). Therefore, those studies and this study had different study designs $(45,46)$. Huang et al reported a $48.5 \%$ rate of CA9 positive expression. They selected patients with HCC that had not received any anticancer therapies (e.g., TACE) before a curative liver resection. Their study design and cohort were similar to those of the present study, and accordingly, the rate of CA9 positive samples was also similar (47).

Expression of CA9 generally predicts a poor prognosis in various cancers $(12-17,46,47)$. The present study showed that CA9 expression was associated with a poor prognosis and early recurrence in HCC. Two previous reports evaluated correlations between CA9 expression and prognosis with immunohistochemical analyses of HCC samples. Kang et al (46) performed immunohistochemical anti-CA9 staining on microarrays of HCC tissues and non-neoplastic liver tissues. They employed a training cohort of 838 patients and a validation cohort of 225 patients. They showed that the CA9(+) group had a worse prognosis than the CA9(-) group, for both the DFS and OS. They also showed that CA9 expression was an independent prognostic factor for DFS and OS in a multivariate analysis. However, the rate of CA9-positive samples was quite low, and some patients in the training cohort had undergone liver transplantation or had received previous treatment for HCC. Furthermore, they could not show a correlation between CA9 expression and DFS in the validation cohort. In another study, Huang et al (47) showed that CA9 expression predicted poor DFS and OS in univariate analyses, but in a multivariate analysis, CA9 expression was only an independent prognostic factor for DFS. That study included 227 patients that had received a hepatectomy for HCC from 1988 to 1996. One limitation of that study was the older age of the cohort. In this study, CA9 expression was an independent prognostic factor for both DFS and OS in multivariate analyses among patients with HCC that spanned a large age range (36-84 years) and had no previous history of treatment.

In the present study, total recurrence rates of CA9 between the positive group and negative group for 10 years after primary curative surgery was similar $62.1 \%$ (36 cases) and $61.0 \%$ (36 cases), respectively. However, overall survival rate of CA9-positive group was higher than that of CA9-negative group. To address this difference, we evaluated the recurrence pattern of our cohort. In the CA9-positive group, 36 cases experienced recurrence and 16 cases (44.4\%) among them have recurrence exceeding the Milan criteria. In the CA9-negative group, 36 cases experienced recurrence and only 6 cases (16.7\%) among them have recurrence exceeding the Milan criteria. This aggresive recurrent pattern could contribute to poor prognosis in the CA9-positive group.

In conclusion, the present study showed that CA9 expression was a pivotal predictive factor for HCC recurrence and prognosis after radical surgery. Our results suggested that one mechanism for enhancing malignant potential was CA9 regulation of the expression of EMT-related molecules. Therefore, CA9 represents a potential therapeutic target for future HCC treatments. Future studies are necessary to confirm the finding that $\mathrm{CA} 9$ expression can enhance malignant potential in HCC.

\section{References}

1. Jemal A, Bray F, Center MM, Ferlay J, Ward E and Forman D: Global cancer statistics. CA Cancer J Clin 61: 69-90, 2011.

2. Lok AS, Seeff LB, Morgan TR, di Bisceglie AM, Sterling RK, Curto TM, Everson GT, Lindsay KL, Lee WM, Bonkovsky HL, et al; HALT-C Trial Group: Incidence of hepatocellular carcinoma and associated risk factors in hepatitis C-related advanced liver disease. Gastroenterology 136: 138-148, 2009. 
3. Yuen MF, Tanaka Y, Fong DY, Fung J, Wong DK, Yuen JC, But DY, Chan AO, Wong BC, Mizokami M, et al: Independent risk factors and predictive score for the development of hepatocellular carcinoma in chronic hepatitis B. J Hepatol 50: 80-88, 2009.

4. Diehl AM: Alcoholic liver disease: Natural history. Liver Transpl Surg 3: 206-211, 1997.

5. Tomimaru Y, Wada H, Eguchi H, Tomokuni A, Hama N Kawamoto K, Marubashi S, Umeshita K, Doki Y, Mori M, et al: Clinical significance of surgical resection of metastatic lymph nodes from hepatocellular carcinoma. Surg Today 45: 1112-1120, 2015.

6. Okamura Y, Ashida R, Ito T, Sugiura T, Mori K and Uesaka K: The tumor marker score is an independent predictor of survival in patients with recurrent hepatocellular carcinoma. Surg Today 45 : $1513-1520,2015$.

7. Wu TH, Hatano E, Yamanaka K, Seo S, Taura K, Yasuchika K, Fujimoto Y, Nitta T, Mizumoto M, Mori A, et al: A non-smooth tumor margin on preoperative imaging predicts microvascular invasion of hepatocellular carcinoma. Surg Today 46: 1275-1281, 2016.

8. Hao S, Fan P, Chen S, Tu C and Wan C: Distinct recurrence risk factors for intrahepatic metastasis and multicenter occurrence after surgery in patients with hepatocellular carcinoma. J Gastrointest Surg 21: 312-320, 2016.

9. Pastorekova S, Ratcliffe PJ and Pastorek J: Molecular mechanisms of carbonic anhydrase IX-mediated $\mathrm{pH}$ regulation under hypoxia. BJU Int 101 (Suppl 4): 8-15, 2008.

10. Swietach P, Wigfield S, Cobden P, Supuran CT, Harris AL and Vaughan-Jones RD: Tumor-associated carbonic anhydrase 9 spatially coordinates intracellular $\mathrm{pH}$ in three-dimensional multicellular growths. J Biol Chem 283: 20473-20483, 2008.

11. Wykoff CC, Beasley NJ, Watson PH, Turner KJ, Pastorek J, Sibtain A, Wilson GD, Turley H, Talks KL, Maxwell PH, et al: Hypoxia-inducible expression of tumor-associated carbonic anhydrases. Cancer Res 60: 7075-7083, 2000.

12. Swinson DE, Jones JL, Richardson D, Wykoff C, Turley H, Pastorek J, Taub N, Harris AL and O'Byrne KJ: Carbonic anhydrase IX expression, a novel surrogate marker of tumor hypoxia, is associated with a poor prognosis in non-small-cell lung cancer. J Clin Oncol 21: 473-482, 2003.

13. Giatromanolaki A, Koukourakis MI, Sivridis E, Pastorek J, Wykoff CC, Gatter KC and Harris AL: Expression of hypoxiainducible carbonic anhydrase-9 relates to angiogenic pathways and independently to poor outcome in non-small cell lung cancer. Cancer Res 61: 7992-7998, 2001

14. Chia SK, Wykoff CC, Watson PH, Han C, Leek RD, Pastorek J, Gatter KC, Ratcliffe P and Harris AL: Prognostic significance of a novel hypoxia-regulated marker, carbonic anhydrase IX, in invasive breast carcinoma. J Clin Oncol 19: 3660-3668, 2001.

15. Tan EY, Yan M, Campo L, Han C, Takano E, Turley H, Candiloro I, Pezzella F, Gatter KC, Millar EK, et al: The key hypoxia regulated gene CAIX is upregulated in basal-like breast tumours and is associated with resistance to chemotherapy. $\mathrm{Br} J$ Cancer 100: 405-411, 2009.

16. Kim HL, Seligson D, Liu X, Janzen N, Bui MH, Yu H, Shi T, Figlin RA, Horvath S and Belldegrun AS: Using protein expressions to predict survival in clear cell renal carcinoma. Clin Cancer Res 10: 5464-5471, 2004.

17. Hoskin PJ, Sibtain A, Daley FM and Wilson GD: GLUT1 and CAIX as intrinsic markers of hypoxia in bladder cancer: Relationship with vascularity and proliferation as predictors of outcome of ARCON. Br J Cancer 89: 1290-1297, 2003.

18. Loncaster JA, Harris AL, Davidson SE, Logue JP, Hunter RD, Wycoff CC, Pastorek J, Ratcliffe PJ, Stratford IJ and West CM: Carbonic anhydrase (CA IX) expression, a potential new intrinsic marker of hypoxia: Correlations with tumor oxygen measurements and prognosis in locally advanced carcinoma of the cervix. Cancer Res 61: 6394-6399, 2001.

19. Thiery JP, Acloque H, Huang RY and Nieto MA: Epithelialmesenchymal transitions in development and disease. Cell 139 871-890, 2009

20. Tsai YP and Wu KJ: Hypoxia-regulated target genes implicated in tumor metastasis. J Biomed Sci 19: 102, 2012.

21. Wu X, Qiao B, Liu Q and Zhang W: Upregulation of extracellular matrix metalloproteinase inducer promotes hypoxia-induced epithelial-mesenchymal transition in esophageal cancer. Mol Med Rep 12: 7419-7424, 2015
22. Tang J, Xiao L, Cui R, Li D, Zheng X, Zhu L, Sun H, Pan Y, $\mathrm{Du} Y$ and Yu X: CX3CL1 increases invasiveness and metastasis by promoting epithelial-to-mesenchymal transition through the TACE/TGF- $\alpha$ /EGFR pathway in hypoxic androgen-independent prostate cancer cells. Oncol Rep 35: 1153-1162, 2016.

23. Svastová E, Zilka N, Zat'ovicová M, Gibadulinová A, Ciampor F, Pastorek J and Pastoreková S: Carbonic anhydrase IX reduces E-cadherin-mediated adhesion of MDCK cells via interaction with beta-catenin. Exp Cell Res 290: 332-345, 2003.

24. Noda T, Yamamoto H, Takemasa I, Yamada D, Uemura M, Wada H, Kobayashi S, Marubashi S, Eguchi H, Tanemura M, et al: PLOD2 induced under hypoxia is a novel prognostic factor for hepatocellular carcinoma after curative resection. Liver Int 32: $110-118,2012$.

25. Sakamoto T, Kobayashi S, Yamada D, Nagano H, Tomokuni A, Tomimaru Y, Noda T, Gotoh K, Asaoka T, Wada H, et al: A histone deacetylase inhibitor suppresses epithelial-mesenchymal transition and attenuates chemoresistance in biliary tract cancer. PLoS One 11: e0145985, 2016.

26. Wang GL, Jiang BH, Rue EA and Semenza GL: Hypoxiainducible factor 1 is a basic-helix-loop-helix-PAS heterodimer regulated by cellular $\mathrm{O}_{2}$ tension. Proc Natl Acad Sci USA 92: 5510-5514, 1995

27. Amann T and Hellerbrand C: GLUT1 as a therapeutic target in hepatocellular carcinoma. Expert Opin Ther Targets 13: 1411-1427, 2009.

28. Kim KR, Moon HE and Kim KW: Hypoxia-induced angiogenesis in human hepatocellular carcinoma. J Mol Med (Berl) 80: 703-714, 2002.

29. Pastorek J and Pastorekova S: Hypoxia-induced carbonic anhydrase IX as a target for cancer therapy: From biology to clinical use. Semin Cancer Biol 31: 52-64, 2015.

30. Griguer CE, Oliva CR, Kelley EE, Giles GI, Lancaster JR Jr and Gillespie GY: Xanthine oxidase-dependent regulation of hypoxia-inducible factor in cancer cells. Cancer Res 66: 2257-2263, 2006

31. Choi JH, Cho HK, Choi YH and Cheong J: Activating transcription factor 2 increases transactivation and protein stability of hypoxia-inducible factor 1alpha in hepatocytes. Biochem J 424: 285-296, 2009.

32. Rankin EB and Giaccia AJ: Hypoxic control of metastasis. Science 352: 175-180, 2016

33. Balamurugan K: HIF-1 at the crossroads of hypoxia, inflammation, and cancer. Int J Cancer 138: 1058-1066, 2016.

34. Zhang L, Huang G, Li X, Zhang Y, Jiang Y, Shen J, Liu J, Wang Q, Zhu J, Feng X, et al: Hypoxia induces epithelial-mesenchymal transition via activation of SNAI1 by hypoxia-inducible factor $-1 \alpha$ in hepatocellular carcinoma. BMC Cancer 13: 108, 2013.

35. Yang YJ, Na HJ, Suh MJ, Ban MJ, Byeon HK, Kim WS, Kim JW, Choi EC, Kwon HJ, Chang JW, et al: Hypoxia induces epithelialmesenchymal transition in follicular thyroid cancer: Involvement of regulation of twist by hypoxia inducible factor- $1 \alpha$. Yonsei Med J 56: $1503-1514,2015$.

36. Matsuoka J, Yashiro M, Doi Y, Fuyuhiro Y, Kato Y, Shinto O, Noda S, Kashiwagi S, Aomatsu N, Hirakawa T, et al: Hypoxia stimulates the EMT of gastric cancer cells through autocrine TGF $\beta$ signaling. PLoS One 8: e62310, 2013.

37. Chiche J, Ilc K, Laferrière J, Trottier E, Dayan F, Mazure NM, Brahimi-Horn MC and Pouysségur J: Hypoxia-inducible carbonic anhydrase IX and XII promote tumor cell growth by counteracting acidosis through the regulation of the intracellular pH. Cancer Res 69: 358-368, 2009.

38. Yu SJ, Yoon JH, Lee JH, Myung SJ, Jang ES, Kwak MS, Cho EJ, Jang JJ, Kim YJ and Lee HS: Inhibition of hypoxia-inducible carbonic anhydrase-IX enhances hexokinase II inhibitor-induced hepatocellular carcinoma cell apoptosis. Acta Pharmacol Sin 32: 912-920, 2011.

39. Lock FE, McDonald PC, Lou Y, Serrano I, Chafe SC, Ostlund C, Aparicio S, Winum JY, Supuran CT and Dedhar S: Targeting carbonic anhydrase IX depletes breast cancer stem cells within the hypoxic niche. Oncogene 32: 5210-5219, 2013.

40. Cavey M, Rauzi M, Lenne PF and Lecuit T: A two-tiered mechanism for stabilization and immobilization of E-cadherin. Nature 453: 751-756, 2008.

41. Nieto MA: The snail superfamily of zinc-finger transcription factors. Nat Rev Mol Cell Biol 3: 155-166, 2002.

42. Kalluri R and Weinberg RA: The basics of epithelial-mesenchymal transition. J Clin Invest 119: 1420-1428, 2009. 
43. Chou YS and Yang MH: Epithelial-mesenchymal transitionrelated factors in solid tumor and hematological malignancy. J Chin Med Assoc 78: 438-445, 2015.

44. Baulida J and García de Herreros A: Snaill-driven plasticity of epithelial and mesenchymal cells sustains cancer malignancy. Biochim Biophys Acta 1856: 55-61, 2015.

45. Luong-Player A, Liu H, Wang HL and Lin F: Immunohistochemical reevaluation of carbonic anhydrase IX (CA IX) expression in tumors and normal tissues. Am J Clin Pathol 141: 219-225, 2014
46. Kang HJ, Kim IH, Sung CO, Shim JH and Yu E: Expression of carbonic anhydrase 9 is a novel prognostic marker in resectable hepatocellular carcinoma. Virchows Arch 466: 403-413, 2015.

47. Huang WJ, Jeng YM, Lai HS, Fong IU, Sheu FY, Lai PL and Yuan RH: Expression of hypoxic marker carbonic anhydrase IX predicts poor prognosis in resectable hepatocellular carcinoma. PLoS One 10: e0119181, 2015. 